\title{
PIVOTAL DECISIONS IN OUTSOURCING ${ }^{1}$
}

\author{
Outsourcing the IT function is more than a simple case of applying quality metrics.
}

In February 2015, Harrison Northman was in Colorado preparing funeral arrangements for his mother who had just passed away due to a prolonged illness. He took a break from this very stressful activity to check in with the office. As Group ICT Infrastructure Manager for premium mattress fabric manufacturer DesleeClama NV (DCGroup), Northman was responsible for all computing technology, networking and communications encompassing all business units globally.

At one point, Northman shook his head in frustration as he listened to missed messages. Gene Corn, Warehouse Manager of the Inman, SC unit, left several. Each message grew more desperate in tone than the previous with the last one exclaiming “...the scanners are down and I can't get in touch with anyone! Help!” Before returning the call, Northman pondered "Why was Pivotal not responding?”

Managed Services Provider (MSP) Pivotal IT (Pivotal) entered a contract in late 2013 with DCGroup subsidiary DesleeClama North America (DCNA) to manage and maintain computing assets on site. Their responsibilities also required they remotely manage service desk incidents and to lead on-site technology infrastructure projects as needed.

Despite Pivotal receiving adequate feedback related to periodic reviews from end-users, there were recurring technology problems on site that delayed production and shipments on a regular basis. These were rooted in organizational and communications breakdowns between the two parties. Consequently, a recently reorganized DCNA executive management team was skeptical of the arrangement. Northman was puzzled by conflicting feedback, leaving him with only a few options to consider:

- Renegotiate the current contract to better fit the revised organizational needs of the company

- Demote Pivotal to a role that better aligned with its core strengths

- Replace Pivotal with another MSP or contract employee

\footnotetext{
${ }^{1}$ Copyright (c) 2019, Grover Walters. This case was prepared for the purpose of class discussion, and not to illustrate the effective or ineffective handling of an administrative situation. Names and some information have been disguised. This case is published under a Creative Commons BY-NC license. Permission is granted to copy and distribute this case for non-commercial purposes, in both printed and electronic formats.
} 


\section{Industry and Company Background}

The mattress bedding market manufactured and distributed mattresses that were generally sold via independent dealers. Manufacturers experienced 23\% growth from \$7 billion in 2011 to \$8.7 billion. This expansion was a sigh of relief to the sector which had been in decline since 2005. The major players in the market were Serta International, Simmons Bedding Company and Tempur Sealy International.

(Rivera, 2016)

Bedding manufacturers relied on a relatively small segment of the textile industry that produced mattress fabric. Mills like DCNA benefited from growth in the market by producing customized premium knitted fabrics for all the major players. It was forecast that the growth would continue.

\section{DesleeClama N.V.}

DCNA parent DesleeClama N.V. (DCGroup) originated in Vichte, Belgium in 1928. At its inception, the company was named Deslee Textiles. The start-up produced and distributed locally woven mattress fabrics called ticking. Seventy-four years later, the company opened Deslee Textiles USA in Atlanta, Georgia as a distribution hub for its major customer Simmons Bedding USA. The expansion did not stop in the USA. In 2004 it acquired P.T. Clama Indonesia and changed the name of the company to DesleeClama N.V. To manage volume and increase capacity, a new 200,000 sq./ft. facility in Zonnebeke, Belgium was completed in 2004. It would serve as a research, manufacturing and distribution center as well as international headquarters. The facility would allow production not only of mattress fabrics, but also production, spinning, and distribution of its own synthetic yarns. As a result of the investments, the company continued to expand to Canada, China, Brazil, Estonia, Poland, Romania, Singapore, South Africa and Spain over a period of eight years.

\section{DesleeClama North America}

Founded in 2002, Deslee Textiles USA, Inc. was a local manufacturer and distributor of mattress fabric with no more than thirty customers. At first the startup was a distribution facility. Annual sales for the first ten years consistently averaged \$12 million and in 2012 a growth spurt put them at \$18 million in annual sales. Increases in sales were attributed to a new fabric finishing process called Breeze. The product was designed to offer mattress owners a 'cooling sensation' as they slept. Mattress manufacturers like Sealy and Tempurpedic adopted new lines of designer fabric. Deslee Textiles' flagship unit was DCGroup in Zonnebeke, Belgium led by Co-CEOs Jos Deslee (Strategy and Operations) and Hans Dewaele (Sales and Marketing). Its annual turnover was around 60MM EUR. In late 2012, new president and managing director, Craig Dunlop renamed the Deslee Textiles to DesleeClama North America Inc.

\section{Challenges in Manufacturing and Logistics}

DCNA did not begin manufacturing until 2004 when it moved into a 75,000 sq./ft. facility in Inman, SC. It would produce large 50 to 100 meter rolls of both knitted and woven mattress fabric. In 2006, due to global economic factors and adequate production capacity at its Indonesian (DCID), Brazilian (DCBR) and Belgian (DCGroup) counterparts, woven mattress fabrics manufacturing was discontinued locally. Instead, circular knitting machines would produce higher-margin, higher-quality fabrics. Woven fabrics, however, were imported at cost from the sister facilities. 
A custom enterprise resource planning system (ERP) called Schaeffer originated from code purchased from a Belgian software company with the same name. Schaeffer ERP was not ready to handle such a sophisticated supply chain scenario. Under increased time pressure, Stefaan Verkest, DCGroup CIO led development of new modules for Schaeffer that were quickly deployed without much testing so that intercompany transactions would be possible immediately. Module design requirements were driven by decisions at an individual-facilities level and not at the DCGroup level, consequently causing a flurry of changes with very little testing and, with it, a flurry of complaints. Due to increased complexity and rapidly-deployed, sparsely-documented changes, Schaeffer was beginning to establish a negative reputation among business units outside Belgium.

Warehouse operations used Schaeffer to control physical inventories. Wireless 2D barcode scanners communicated directly with Schaeffer to track rolls of fabric coming off knitting machines as it visited each stop in the chain until it left the shipping dock. Schaeffer communicated with the scanners via WIFI and Microsoft Windows remote desktop sessions (staff commonly referred to as RDP). Remote Desktop Protocol or "RDP" sessions allowed simultaneous user interaction with programs installed on a single server. A material handler would manipulate a program in the RDP session to adjust inventory appropriately. When a break occurred in WIFI communication or the RDP server, the material handler would need to wait until the session was restored to continue a warehouse task. As such, WIFI or RDP outages lasting longer than five minutes severely reduced warehouse efficiency.

\section{DCNA IT and Operations}

\section{Role Transition 1.0}

Northman joined DCNA in October 2005 as the unit's Director of IT. Being a solo operation, his responsibilities at that time were split between strategic management, incident management, business process analysis, application developer and database developer tasks. The job would evolve over time as Deslee and Verkest tasked Northman with solving serious reporting performance issues at the DCGroup level. Northman traveled on a regular basis to the core sites in Belgium, Brazil and Indonesia to this end.

As Northman performed site surveys for each business unit involved in the reporting project, he uncovered a very old, heterogenous server, networking, and communications infrastructure. He crafted a separate report detailing storage and computing deficiencies as well as a need for better management of such resources. Some of the storage and computing deficiencies were resolved as part of the reporting project. But there were still many outstanding problems related to networking and communications. Also absent were global standards for Internet use, technology asset procurement, disaster recovery and general IT governance. Northman presented the findings and his five-year strategy to resolve these potentially enterprise-crippling issues to his superiors. By December 2008, the management team agreed that a Group ICT Infrastructure Manager role should be created and that Northman should be appointed to it.

In his new role, Northman would no longer perform any business analyst or software development tasks at DCNA. Instead he would be devoted to computing, communications and networking management tasks globally, while still performing local infrastructure tasks at the struggling DCNA facility. The effort split would be devoted to global (group) management of eight direct reports and two managed services providers at a growing number of international manufacturing and distribution sites. The rest of the effort would be devoted to the local infrastructure at DCNA. This arrangement would remain unchanged until June of 2012. 


\section{Managing Director, Transition and Growth}

Actions taken by the DCGroup board in summer of 2012 would signify the beginning of a very volatile business culture at DCNA (still called Deslee Textiles USA at that time). The volatility began when president, Bart Dehaerne vacated his role to become president of Poppies, USA in North Carolina. In his place, Craig Dunlop would fill the position, beginning in August 1, 2012.

Self-admittedly, Dunlop was not someone who had very much patience with technology. And he was not comfortable attempting to describe a technology problem over email or telephone. His desire was to simply have someone come look at the problem and immediately fix it.

Notwithstanding, Dunlop inherited a research directive with the purpose of developing a proprietary fabric finishing process for a potentially major customer. If successful, the process would lead to tripling of gross sales income within a few years. As it turned out, by the end of 2012, the process was successful and orders for new lines of fabric were finally being placed.

The new injection of cash was applied to expanding both warehouse and manufacturing capacity as well as define a strategy to renew interest in bedding and mattresses by offering more "fashionable knitted fabrics.” Just as Tempurpedic transformed the mattress market with its trademark foam design, Dunlop wanted to do the same with the fabric that wrapped the foam form. The strategy paid off. Within six months, orders for trendier fashionable knitted fabrics were rolling in.

The near-overnight success of the new lines of fabric brought about significant challenges regarding manufacturing and warehouse capacities. New challenges would mean more production shifts and more people. Dunlop also wanted to expand and redefine sales territories. By the end of 2013, the name of the company was changed to DesleeClama North America and, for the first time in company history, the sales budget would grow beyond $\$ 15$ million. The number of employees tripled and so did the need for more IT assets and computing capacity.

\section{Role Transition 2.0}

Growth was not limited to DCNA. The Brazilian business unit (DCBR) was also in the same situation. Moreover, the DCGroup board was also in the process of expanding its global footprint to Estonia, South Africa, Poland and China. From an IT perspective, expansion meant new infrastructure projects that fitted the facilities with necessary business and manufacturing support technologies. Essentially, Northman needed to duplicate the DCNA systems model and apply it to the new startups. Consequently, the expansion added more points of presence and thus more complexity and data load on the wide area network (WAN). The WAN connected the business units together as if they were all working in the same building. Northman would also need to ensure the success of an urgent major upgrade of server and networking architecture at DCGroup.

Managing the success of all the new global projects began to overwhelm Northman as he also acquired new DCNA technology initiatives. Knowing his travel schedule and direct effort applied to global projects would dramatically increase, Northman provided a report detailing the need for his replacement. Again, management agreed with his assessment and decided to dedicate Northman to the Group ICT Infrastructure role, leaving his position at DCNA open. Consequently, the IT Director position was eliminated and in its place the role Infrastructure Responsible (IR) was created. The IR task scope included planning, budgeting, procuring and maintaining computing hardware, networking and communications. Despite his diminishing presence at DCNA, Northman was now responsible for hiring and managing the new position. As such, he would require someone who could work autonomously during the weeks Northman was away from the USA facility. 
Once the position was identified, it was necessary to begin a search. But there was one final caveat before beginning. For reasons unspecified to Dunlop and Northman, the Infrastructure Responsible role was to be outsourced to a contractor who specialized in IT functions. Some managers were skeptical of the idea because there was already so much change occurring in the organization at the time. Knowing there would be a potential cultural shift by users interacting with a vendor instead of an employee, DCNA management was not comfortable charting this "new territory" in such an actively changing and complex business environment.

Northman made attempts to uncover Verkest's justification for the move. Most likely fatigued by the questions, Verkest finally stated “...you need to talk to Jos during his next visit.” Northman finally met with Jos who gave adequate justification for the requirement. Northman understood the motivation behind the move and relayed the sentiment to DCNA management. While still a bit uneasy about the transition, they were nonetheless motivated to move ahead.

Now the search would begin in earnest.

\section{The Search}

Before starting the process of hiring a managed services provider (MSP), Northman attempted to do some research about the benefits and challenges related to the relationship.

\section{What is a MSP?}

A Managed Services Provider was considered a vendor that offered a variety of IT functions in an organization. Northman interviewed peers who had already established such a relationship in their organization. He sought to understand the justification through a set of benefits and challenges described in basic terms as follows:

Benefits: (Essent, 2009)

- The opportunity to scale up or down effort applied to both daily tasks and projects

- Ensures fast-changing technology remains current

- An array of specialized skills is available when projects dictate the need

- Forces clarity in the definition of quality metrics used to govern the department

- Variable costs structure. Pay for what you need when you need it

Challenges:

- MSP's lack of customer organizational and cultural awareness may cause priorities of the MSP to clash with those of the customer's internal stakeholders

- Ownership in task execution and follow-up can be problematic due to the arms-length nature of the relationship (Chron, 2010)

Using information yielded from the research, Northman developed a weighted set of requirements used to evaluate the MSPs during the Request for Proposal (RFP) process (see Exhibit 1). 


\section{The Selection}

The Greenville, Spartanburg SC area was not represented well with MSP vendors. It became difficult to find a vendor that would be a good fit in terms of price and requirements satisfaction. The vendors that could meet all or most of the requirements were very expensive. The costs for such entities were nearly twice that of hiring just one full-time employee (FTE). eGroup was the most expensive at \$9280/mo. Other candidates were very small operations with one or two individuals that could only satisfy a handful of the requirements.

Only two companies could provide more than half of the requirements. Atkins Data \& Telephone Services (Atkins) with a monthly cost of \$3900 and Pivotal ITS (Pivotal) with its monthly cost at \$4440. Pivotal was chosen because they offered a very mature service desk that Atkins could not offer. See the selection document used to evaluate requirements fit in Exhibit 2.

\section{Contract Finalization and Onboarding}

After Pivotal was informed of their selection, they went to work drafting the contract which included, in Northman's opinion, a reasonable SLA (see Exhibit 3).

At its core, the service responsibility would be as follows:

- $\quad$ Strategic Consulting Services

o Network Design

o Asset Management

o Network Documentation

o Executive Review Sessions

o Procurement Services

o Vendor Review

- Proactive Solutions

o System Maintenance

o Patch Management

o Remote Monitoring

- Reactive Support Services

o Help Desk Support

o Remote Engineering

- Disaster Recovery

o Backup Management

After the contract was signed in November 2013, the onboarding began. Onboarding was a process of introducing the MSP to the company and integrating them into the daily processes. Doing so involved an inventory phase where details about standard operating procedures (SOP) and IT assets were collected and assimilated into the MSP(s) master data. Pivotal completed the inventory phase by the end of December 2013 and was ready to begin full service starting January 1, 2014.

\section{Quality Metrics and Administration}

Northman collected data to be used in a periodic report sent only to his superiors, Dunlop and Verkest. Certain quality metrics were already defined and established at all of the business units globally.

The quality metrics used to evaluate Pivotal's performance were very simple. Also added was a subjective feedback survey to gauge user sentiment. Since the practice of employing an MSP was relatively new, 
Northman wanted to review any positive, but primarily any negative feedback from users so that proper adjustments could be made to agreement. Performance metrics used for this relationship were as follows:

Metrics used:

- Efficiency - total open incidents / total closed incidents

- Average Effort Hour - average of the actual time in hours applied to resolving incidents

Feedback Survey Questions:

- Is the availability of the service desk sufficient for you?

- Are the response times acceptable?

- How do you rate the technical knowledge of the service desk?

- Is the service desk working as you would expect?

- How do you rate the communication and follow-up problem resolution?

- Is the time to resolve the problem acceptable?

- How do you rate the communications skills of the service desk?

- Overall quality of the service desk?

\section{Positive Results}

The metrics revealed Pivotal was progressing in a satisfactory manner. Actual reporting of quality metric data can be found in Exhibit 4.

Feedback Survey results appeared to be always improving with the question "Overall Quality of the Service Desk?”

“Over $70 \%$ of users have a favorable opinion of the service desk...”. The absence of negative feedback in this area means that we are moving in a positive direction. More can be done, of course to improve those numbers to 100\% favorability” (see Exhibit 5 for complete survey data).

\section{Challenges}

Northman considered Pivotal to be the IT presence at DCNA. For the first quarter of service coverage he widened his threshold of expected performance as defined by the Service Level Agreement (SLA). Knowing there would be issues getting comfortable with the relationship, he tolerated frequent instances of service desk unavailability, end-user confusion about who to contact when an incident occurred, lapses in recalling knowledge defined in their master data and weak project supervision. However, similar issues persisted until September 2014 when calls were initiated by Dunlop to “...do something about all the computer problems!”.

Northman attempted to assist Pivotal by creating and granting write access to a shared Microsoft OneNote file containing standard operating procedures, documentation and change logs technicians could consult and update when performing required tasks. Pivotal agreed to share the document with their staff. See Exhibit 6 that illustrates the usage of the document.

In addition to internal IT challenges, almost all management team members at DCNA were replaced in 2012. Only Dunlop and Connie Valenti, VP of Finance remained while new executive positions were created and existing roles redefined. The changes introduced a volatile effect on headcount and turnover 
in the organization. As such, there was intense pressure on Pivotal to handle employee changes quicklymeaning that IT user provisioning procedures needed to be completed within hours of the decision. See a categorical breakdown of effort provided by Pivotal for 2014 in Exhibit 7.

\section{Summary and Conclusion}

\section{Summary}

By February 2015 Northman was at a crossroads. He was faced with conflicting views regarding the outsourcing directive. DCGroup's management team requires that all sites outsource the local IT service desk and related technology projects. On the other hand, DCNA's management team was still not satisfied with this type of arrangement. As a result, Northman realized he should improve and expand operational visibility. Instead of sending his reports to Dunlop and Verkest only, he would, instead, send to all DCNA executive managers and, if necessary, present it at one of the periodic board meetings. Everyone would then be able to see evidence of user satisfaction and project status. Doing so would hopefully mitigate negative bias by management of this type of arrangement. In addition to improving transparency, Northman begins to contemplate options that would further improve the perception of IT performance at DCNA.

\section{Revise and Better Enforce the SLA}

The first option considered was to renegotiate the contract with Pivotal to redefine the SLA based on a level more compatible with Northman's and, by extension, management team expectations. More importantly, Northman would better enforce SLA with regards to project quality and duration. Advantages and disadvantages of choosing this option were apparent. Benefits would include incurring no new costs associated with onboarding a replacement for Pivotal. Project completion rate and quality should improve, thereby mitigating some of the more pressing chronic issues related to warehouse and logistics. The main disadvantage would involve potential risk related to Pivotal and its ability to complete projects in a timely, qualitative and cost-effective manner.

\section{Reduce Pivotal's Role to Remote Service Desk Only}

Another option considered was to renegotiate the contract in a way that limits Pivotal's scope of responsibility to remote service desk only. Northman would then employ one or more vendors to execute projects and on-site maintenance. Doing so would give Northman desired control and flexibility to switch or even add vendors as needed. Project completion rates should increase and relieve chronic issues plaguing the company. A disadvantage considered was that Pivotal might decline any new arrangements-potentially generating overhead in selecting and onboarding a new MSP. Consequently, users might have to contend with a change in service desk personnel. Project and hourly billing for on-site maintenance costs could potentially increase if the new vendors would not match Pivotal's reduced package rate.

\section{Hire Full-Time On-Site Contractor}

A final option Northman considered was to simply end the contract with Pivotal. In their place, he would hire a full-time contractor through an agency. Doing so would imply someone was always on site for urgent service desk issues. Northman would have full control over project management. With his direct oversight, projects may be completed on time and chronic issues relieved. Dunlop expectations for immediate assistance would be satisfied. On the other hand, more effort would need to be applied to initial training and retraining of individual contractors. Northman would also forfeit the benefits of a MSP relationship. 


\section{References}

Rivera, E. (2016). IBISWorld industry report 33791: Mattress Manufacturing in the US. Retrieved from https://www.ibisworld.com/industry/default.aspx?indid=876

Essent (2009). The top 10 benefits of outsourcing it through managed services. Retrieved from https://www.essent.com/News/Blog/The-Top-10-Benefits-of-Outsourcing-IT-throughManaged-Services-284-24.htm

Chron (2010). Benefits vs. risks of outsourcing IT services. Retrieved from http://smallbusiness.chron.com/benefits-vs-risks-outsourcing-services-2504.html

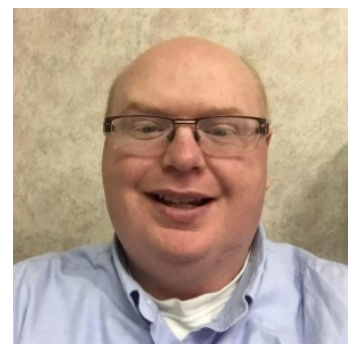

\section{Author}

Grover Walters, a graduate of the University of South Carolina, Upstate with a Bachelor of Science in Computer Science also earned a Master of Science in Information Technology from the Florida Institute of Technology and is pursuing a Doctor of Business Administration at the University of South Florida. In addition to his education, he offers more than 25 years of experience in information technology and communications governance, strategic planning and influence of mid-level enterprises to his courses in programming, database architecture, business intelligence, executive information technology management, project management, information science and information technology management he teaches at his alma mater the University of South Carolina, Upstate. 


\section{Exhibit 1: Request for Proposals Document}

\section{RFP - IT Managed Services Provider}

Monday, September 9, 2013 9:02 AM

\section{Overview}

DesleeClama North America is seeking an IT Services vendor to provide incident management, hardware support, procurement services and project management.

\section{Company Information}

DesleeClama North America is located in Inman, South Carolina. The company manufactures and distributes globally woven and knitted products. The operation employs 100 staff members, of which 30 are managed end-users.

\section{Technical Scope}

End-user devices (laptops, desktops, phones etc...): 90

VMware Physical Hosts: 2

VMware Virtual Servers: 14

Network devices (routers and switches): 20

\section{Service Level Requirements}

1. Initial point of contact. All user calls and e-mails will be directed to you first. Decide what your scope of responsibility. Items within scope should be triaged and scheduled for resolution. Forward anything out of scope to the Applications group in Belgium.

2. Summarized Weekly, Monthly and Quarterly reporting of all responsibility domains including any projects. Supporting detail data must be included with any report.

3. Remote support calls should be acknowledged within 1 hour and resolution started within a 4-hour period. Resolution should be within 24 hours where possible.

4. Standard On-Site support calls should be handled during the next scheduled onsite visit.

5. Emergency On-Site support calls (related to network switch/wifi or fiber problems only).

6. Any work outside the scope of responsibility should be presented in the form of a project, including a basic scope, work breakdown structure, estimated costs of materials, estimated effort in time and dollars, and estimated duration in time. 
MUMA CASE REVIEW

\section{Exhibit 2: Weighted Selection by Requirements}

\section{Weighted Selection - IT Managed Service Providers}

\section{Requirement}

Price (scored 1 highest, 3 for lowest)

Initial point of contact. All user calls and e-mails will be directed to you first. Decide what your scope of responsibility. Items within scope should be triaged and scheduled for resolution.

Forward anything out of scope to the Applications group in Belgium. (scored 3 best fit, 3 for least)

Summarized Weekly, Monthly and Quarterly reporting of all responsibility domains including any projects. Supporting detail data must be included with any report. (scored 3 best fit, 3 for least)

Remote support calls should be acknowledged within 1 hour and resolution started within a 4hour period. Resolution should be within 24 hours where possible. (scored 3 best fit, 3 for least)

Standard On-Site support calls should be handled during the next scheduled on-site visit. (scored 3 best fit, 3 for least)

Emergency On-Site support calls (related to network switch/wifi or fiber problems only). (scored 3 best fit, 3 for least)

Any work outside the scope of responsibility should be presented in the form of a project, including a basic scope, work breakdown structure, estimated costs of materials, estimated effort in time and dollars, and estimated duration in time. (scored 3 best fit, 3 for least)

Selection Score

Weighted Average

Rank

Weighted Requirement Score is calculated as [requirement weight] * [fitness score]

Weighted Average is the average of all weighted requirement scores
Candidates

Weighted Requirement Score

Requirement

Weight

eGroup Pivotal Atkins

3

3

9

9

9

2

\section{6}

6

2

\begin{tabular}{|c|c|c|}
\hline 9 & 9 & 9 \\
\hline 3 & 3 & 3 \\
\hline
\end{tabular}

\begin{tabular}{|c|c|c|}
\hline 6 & 6 & 2 \\
\hline 38 & 48 & 34 \\
\hline 43 & 6.86 & 4.86 \\
\hline 3 & 1 & 2 \\
\hline
\end{tabular}


WALTERS

\section{Exhibit 3: Pivotal Service Agreement}

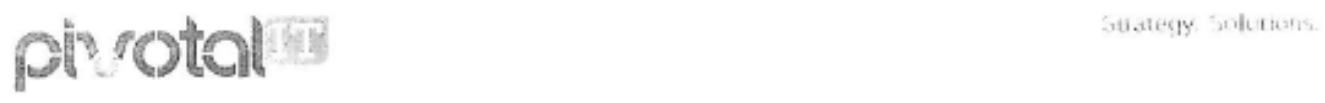

\section{Monthiy Managed IT Plan - Silver with Block Hours}

SECTION 1: AGREEMENT

Pivotal IT (hereinafter referred to as "Service Provider") and Deslee Clama (hereinafter referred to as "Client") hereby agree that the Service Provider will provide IT (Information Technology) services in accordance with the term5 and responsibilities outlined within this agreement.

\section{SECTION 2: INCLUDED SERVICES}

Strategic Consulting Services

- Network Design - The Service Provider will assist with developing a network design intended to improve the overall security, stability, and performance of the client's Ir environment. This may include but is not limited to server and client implementation, email and communication solutions, backup management solution, system and network security solutions.

- Asset Management - The Service Provider will assess and analyze the usefulness and sufficiency of current network/system devices. The Service Provider will then propose a plan for maximizing their life-cycle with recommended replacement assets and replacement dates.

- Network Documentation - The Service Pravider will complete initial documentation of critical information relating to the hardware, software, pas5words, configurations and other details regarding the components of the Client's computer network. This information will be presented to the Client upon completion in a binder format and will be updated as core aspects of the Client's network change.

- Executive Review Sessions- On a scheduled basis, your Account Manager will meet with you and/or key members of your team to review service history, satisfaction, action plan items, and upcoming priorities.

- Procurement Services - At the request of the Client, the Service Provider will research, specify, and procure any replacement hardware or software within the Client's network so far as the Service Provider has availability and competence in sourcing such products.

- Vendor Review - On the Client's behalf, the Service Provider will review computer technology services provided by third party vendors to the Client with regard to services provided, services billed, and services needed. The Service Provider may make recommendations to the Client after such reviews.

Proactive Solutions

- System Maintenance - All systems falling within the scope of this agreement will have maintenance routines performed at a minimum of a monthly basis. These routines include, but are not limited to, disk defragmentation, temporary file removal and event log reviews.

- Patch Management - All desktops falling within the scope of this agreement will be patched weekly. Out of band critical patches will be deployed on an as-needed basis. This includes but is not limited to operating system patches, Microsoft Office patches, Adobe patches, and endpoint security software provided by the Service Provider.

- Remote Monitoring - The Service Provider will install monitoring software on servers, desktops and laptops falling within the scope of this agreement. When actively reporting, the agent will send information including but not limited to alerts notifying us of disk drive fallure, insufficient drive space, server offline, and internet connectivity failure.

Reactive Support Services

- Help Desk Support - All employees covered by this agreement will have unlimited access to the Service Provider's Help Desk. The Help Desk is meant to be the first level of support for common end- 
MUMA CASE REVIEW

\section{pirsotal}

staiegy ioineter.

user technical issues such as PC Support, slow internet, missing icons, virus infections, spyware infections, printer issues, software support and basic how to questions etc.

- Remote Engineering - This service is meant for issues beyond Help Desk level expertise including server diagnostics, VPN Support, network configurations, Active Directory modifications, and Group Policy modifications. This level of support is engaged after an issue has been initially analyzed by the Help Desk.

Additional Included Services

- Backup Management

- Monitoring of backup successes and failures

a Remediation of failed backup resulting from imaging software and related services

- 1 Terabyte (1000 Gigabytes) of offsite storage at redundant data centers

- Confirmation of offsite backup success

- Imaging software for covered systems

- Note: In the event of a disaster, hardware failure, security breech, malware infection, or any other situation that creates a need for data recovery or a system reload, the Service Provider will provide the required service for an hourly rate of $\$ 115.00$ billed in $y_{4}$ hour increments after an initial 1 hour minimum. If such service is needed, please direct your request to our Help Desk at 864-253-1984.

SECTION 3: Additional Billable Services

The Following Services are Available at the hourly rate associated with the agreement. These services may also draw from any associated block time.

- Advanced Engineering - This includes the physical setup, troubleshooting, or repair of hardware / software on-site or off-site. This level of support is engaged after an issue has been initially analyzed by the Help Desk.

- Vendor Management - On the Client's behalf, the Service Provider will provide assistance with managing third party vendors that impact the Client's network including but not limited to printer and copier companies, internet providers, software providers, and phone service providers.

- Firewall/Network Management - The Service Provider will provide firewall management including the support of routine functions such as Virtual Private Network (VPN) connections, Basic Access Control, port management, and monthly checks for updates to the firewall's firmware.

For services not covered by this agreement, the Client may pay by one of the two following methads:

1. An hourly rate of $\$ 115.00$ per hour

2. Flat Rate Project Pricing

The following services are not included as part of the Client's monthly agreement. Unless otherwise stated, the client is entitled to these services at their discounted hourly rate or stated monthly price:

- Infrastructure Changes - Server/system implementations, switches, firewalls, network printers, Wireless LAN, cabling, office moves, company mergers etc.

- Non-business Support - Home network and personal applications support

- Unsupported Devices - Tape Backup, Unwarranted Servers, Desktops >5 years old, Apple and/or Windows Operating Systems not supported by manufacturer, outdated hardware, white box computers

SECTION A: SERVICE LEVEL.

The following metrics will be reached greater than or equal to $90 \%$ of the time during normal weekday business hours for 5ystem and/or network issues with a high severity (effect to critical operation functionality) and high impact (breadth af effect within the company operations):

- Response Time - Within 1 business hour 
WALTERS

pircotal

Stranedy. Soiutur.

- This is the amount of time it may take the Service Provider to recognize and be aware of the Client's request.

- Time to Service - Within 4 business hours

- This is the amount of time it may take the Service Provider's Engineer to begin the troubleshooting process to remediate the system/network issue.

SECTION 5: LOCATIONS

This agreement provides the services stated in Section 2 for the location/s listed below:

- 1880 Campton Rd., Inman SC 29349

SECTION 6: HOURS OF SERVICE

Weekdays - The Service Provider shall be available from:

- gAM to 5PM Eastern Time, Monday through Friday. The Service Provider is closed on most Federal Holidays.

Weekends - Emergency support services may be available outside of normal business hours on weekends for an additional per request fee of $\$ 295$ plus 1.5 times ( 2 times on Sunday) the Client's project rate with a 1 hour minimum. This service is best effort. It is available as a first come, first served basis. It is provided from:

- Saturday 8AM to 5 PM and Sunday 1 PM to 5 PM.

See Pivotal IT Weekend Emergency fiesponse Document for additional details.

SECTION 7: AGREEMENT PERIOD AND EFFECTIVE DATE

This agreement is for 1 year and auto renews on a month to month basis thereafter.

- Effective Date: Beings: 12/1/2013

Ends: $11 / 30 / 2014$

SECTION 7: TERMINATION

The Client may terminate this agreement by written notice within the first 30 days of the agreement's effective date. While it is the Service Provider's goal to maintain a long term mutually beneficial business relationship, it is understood that situations beyond control may force the dissolution of this agreement. Therefore, at any time after the initial 30 days of this agreement's effective date, the client may withdraw from the terms of this agreement by paying ten (10) percent of the remaining value of the Client's contract. The Service Provider maintains the right to terminate this agreement at any time with 30 days written notice. There will also be a 90 day satisfaction review to confirm the value of this agreement to the Service Provider and the Client. Please be aware that all subscription software will be uninstalled and all subscription services will be deactivated upon termination. Customer agrees to allow service provider physical access to all devices, as necessary, to uninstall subscription software and/or deactivate subscription services.

SECIOH 8: NETWORK COMPLANCF.

The Service Provider reserves the right to refuse to support any unlicensed software. The Service Provider reserves the right to bill the Client at their discounted hourly rate for repeat issues arising from failure to comply with our formally recommended best practices. This may include maintaining an Acceptable Use Policy (AUP), replacing endof-life or defective hardware, having a managed backup and security device, and/or maintaining warranty coverage on critical network devices.

SECTION 9: LIMITARIONS

By signing this agreement, the client understands that the Service Provider will use its best efforts to accomplish the work described herein. The Client understands that no computer system is foolproof, and there are limitations imposed by the Client's existing system, the hardware, the software and prior and existing business practices which will affect the ability of the Service Provider to accomplish its goals. The Service Provider will provide the client with their best advice, but the extent to which that advice is followed will affect the results. The Client's system can also be affected by acts of God, acts of others, failure to follaw proper procedures, civil war, insurrection or riot, fire, 
Flood, explosion, earthquake or serious accident, strike, labor trouble or work interruption, loss of an IP address or other disruption to internet connection. Consequently the Sevvice Provider cannot guarantee particular results. The Service Provider will not be liable for lost profits, loss of business or other consequential, special, indirect, or punitive damages, even if advised of the possibility of such damages, or for any claim by any third party except as expressly provided herein.

\section{SECTION 10: BULLING POLICIES}

Amounts not paid within thirty days from the invoice date will be subject to a late payment charge of $1.5 \%$ per month. If for any reason the account is turned over to an attorney for collection, reasonable attorney fees will be added to cover collection costs. By accepting this engagement letter, the client agree that this Service Provider is relieved from performing any further work should the Client not comply with the terms of the fee arrangernent stated herein. Work may be suspended without further notice to the Client if the Client's account becomes 60 days or more coverdue and will not be resumed until the Client's account is paid in full.

SECTION 11: PRICING

The Client hereby agrees to pay the Service Provider to furnish services listed in Section 2 of this agreement for the locations listed in Section 5 of this agreement for the following monthly investment:

\begin{tabular}{|l|c|c|c|}
\hline Monthly Gold Managed IT Agreement & Quantity & Price & Extended \\
\hline Item & 35 & $\$ 65.00$ & $\$ 2,275.00$ \\
\hline Primary Users - Silver & 10 & $\$ 65.00$ & $\$ 650.00$ \\
\hline Managed Servers & 45 & $\$ 0.00$ & $\$ 0.00$ \\
\hline System Agents & 1 & $\$ 155.00$ & $\$ 155.00$ \\
\hline Backup Management-1 Terabyte & 16 & $\$ 85.00$ & $\$ 1,360.00$ \\
\hline Monthly onsite hours & & & $\$ 4,440.00$ \\
\hline Monthly Total & & & \\
\hline
\end{tabular}

\begin{tabular}{|l|c|c|c|}
\hline One Time Fees & Quantity & Price & Extended \\
\hline Item & 1 & $\$ 2,925.00$ & $\$ 2,925.00$ \\
\hline $\begin{array}{l}\text { Setup Fee (First Month's Fee Less Backup } \\
\text { Management) }\end{array}$ & & & $\$ 2,925.00$ \\
\hline
\end{tabular}


WALTERS 
Exhibit 4: Basic Metrics Applied - DCNA

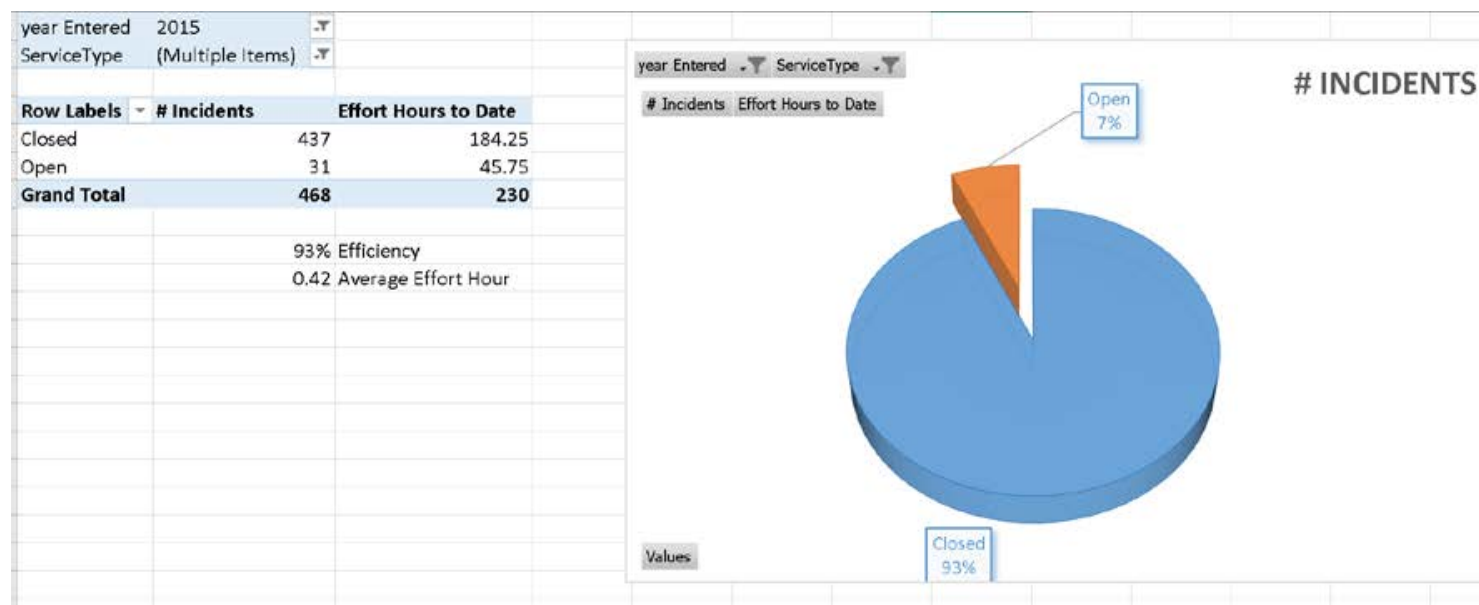




\section{Exhibit 5: Feedback Survey}

Feedback Survey Results

The following survey was published November $8^{\text {th }} 2014$. Eleven of 38 users responded $(29 \%)$ to the questions as of November $15^{\text {th }}$. I will respond to each question individually followed by a summary statement with action items.

Q1

\section{Customize Export -}

Is the availability of the Service desk sufficient for you?

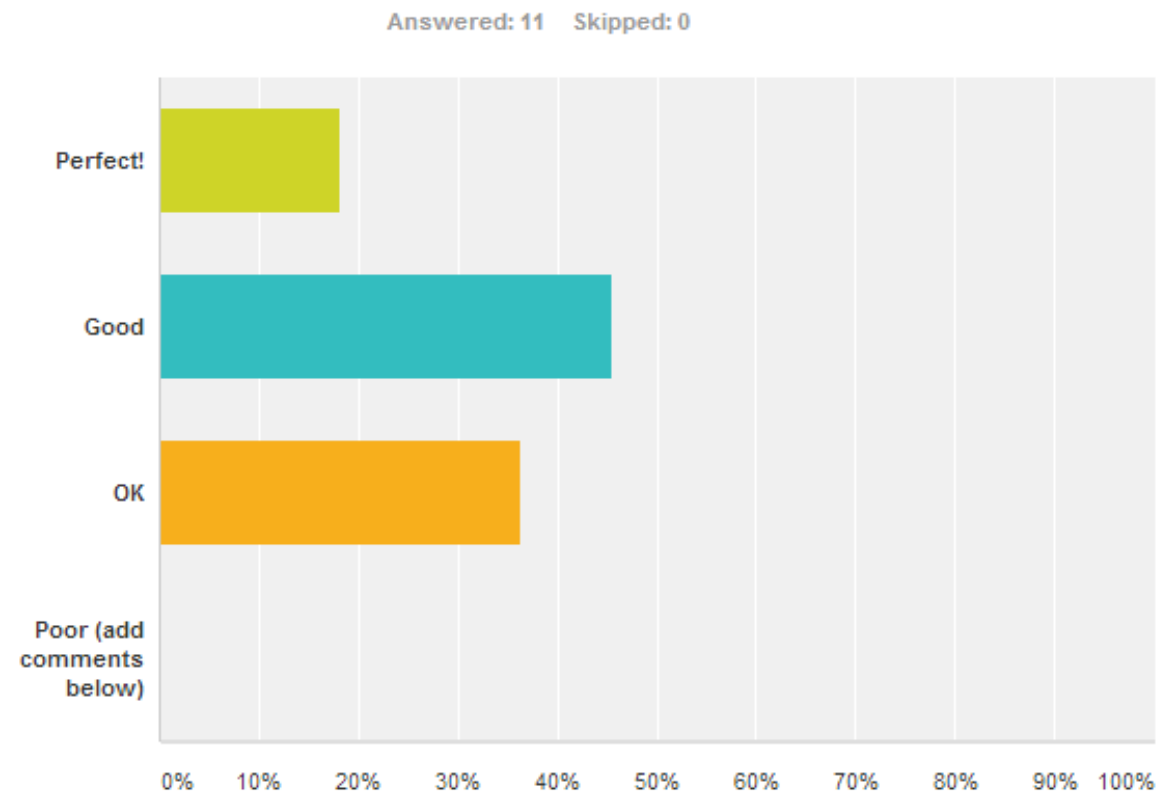

\begin{tabular}{l|lc}
\hline Answer Choices & Responses \\
\hline$\quad$ Perfect! & $\mathbf{1 8 . 1 8 \%}$ & 2 \\
\hline$\quad$ Good & $\mathbf{4 5 . 4 5 \%}$ & 5 \\
\hline$\quad$ OK & $36.36 \%$ & 4 \\
\hline$\quad$ Poor (add comments below) & $0.00 \%$ & 0 \\
\hline Total & & 11 \\
\hline
\end{tabular}

Comments (0)

Nearly $64 \%$ of users have a favorable opinion of the availability of the service desk, meaning the window of opportunity for help is sufficient to most users. 


\section{Are the response times acceptable?}

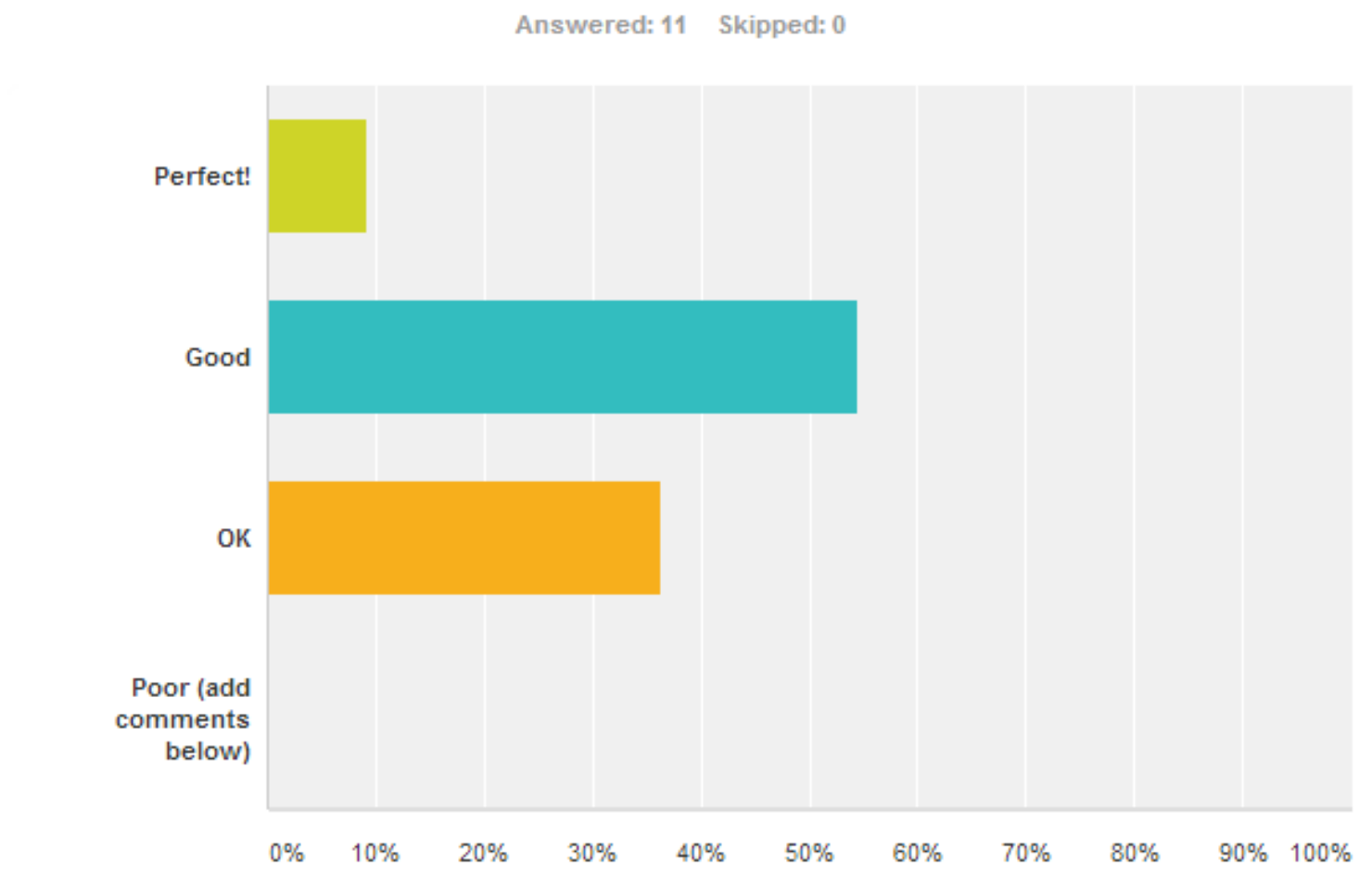

\begin{tabular}{l|lc}
\hline Answer Choices & Responses \\
\hline Perfect! & $\mathbf{9 . 0 9 \%}$ & 1 \\
\hline Good & $\mathbf{5 4 . 5 5 \%}$ & 6 \\
\hline OK & $\mathbf{3 6 . 3 6 \%}$ & 4 \\
\hline$\quad$ Poor (add comments below) & $\mathbf{0 . 0 0 \%}$ & 0 \\
\hline Total & & 11 \\
\hline
\end{tabular}

Comments (0)

Nearly $64 \%$ of users have a favorable opinion of the response times of the service desk, meaning the service desk does a satisfactory job in acknowledging the service request and making initial contact with the user. In most cases, a user gets an e-mail response from the service desk within 5 minutes of submitting the request. 


\section{How do you rate the technical knowledge of the servicedesk?}

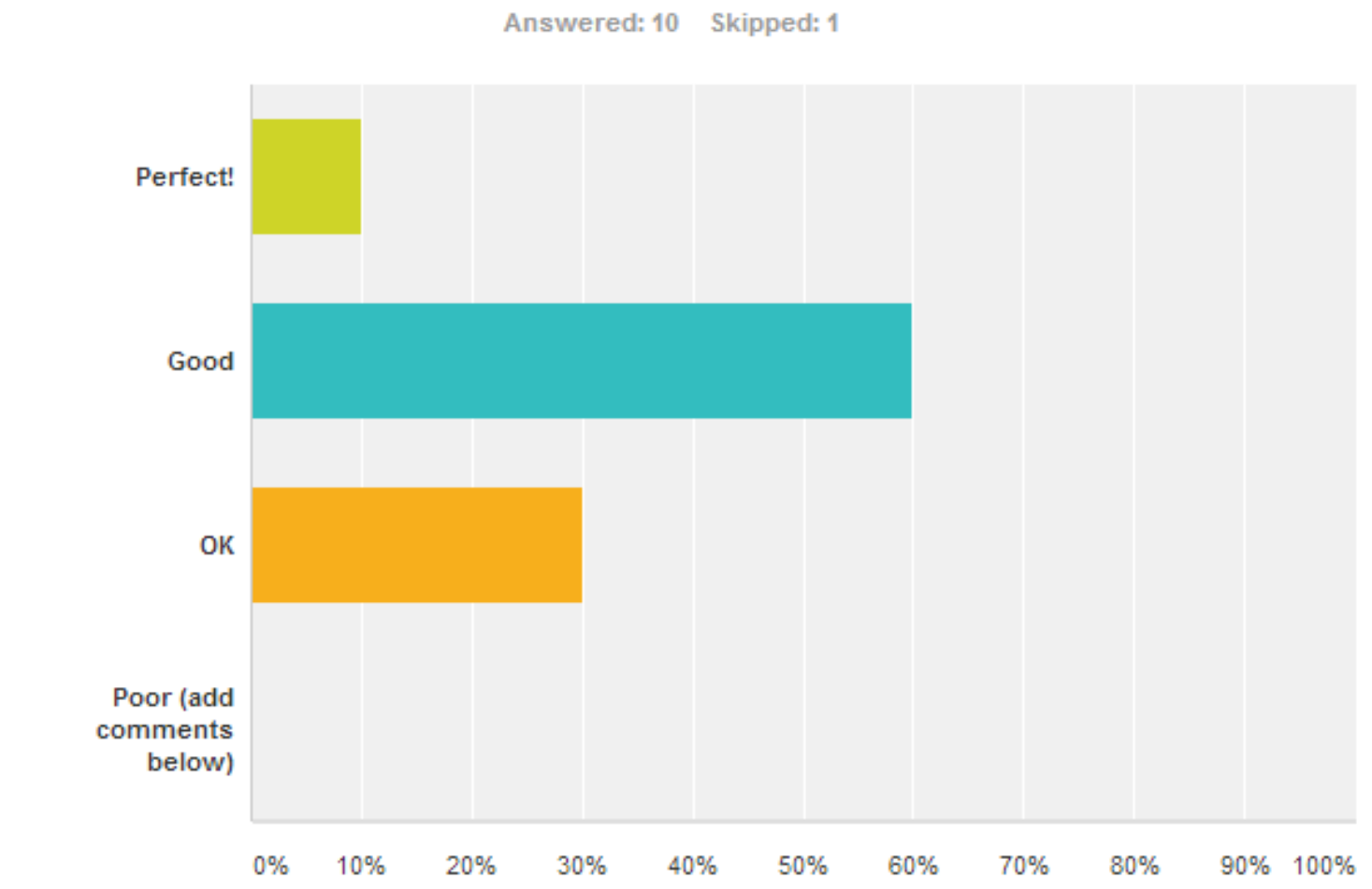

\begin{tabular}{l|lc} 
Answer Choices & Responses \\
\hline Perfect! & $\mathbf{1 0 . 0 0 \%}$ & 1 \\
\hline Good & $\mathbf{6 0 . 0 0 \%}$ & 6 \\
\hline$\quad$ OK & $\mathbf{3 0 . 0 0 \%}$ & 3 \\
\hline$\quad$ Poor (add comments below) & $\mathbf{0 . 0 0 \%}$ & 0 \\
\hline Total & & 10
\end{tabular}

Comments (0)

$70 \%$ of users have a favorable opinion concerning the technical knowledge of the service desk technician. This will improve over time as all of the service desk staff become more familiar with DesleeClama North America ICT operational processes, assets and structure. 


\section{Is the service desk working as you would expect?}

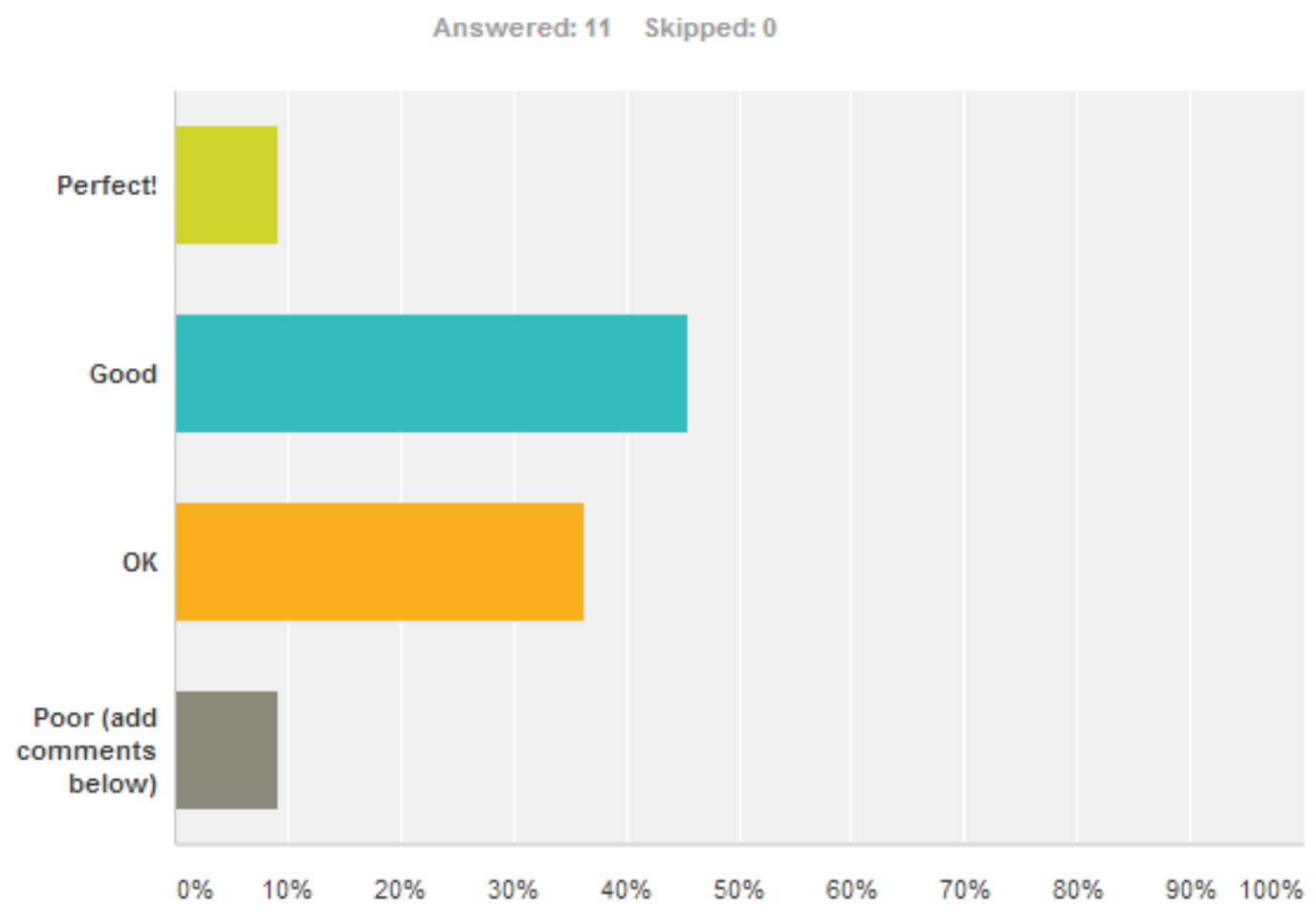

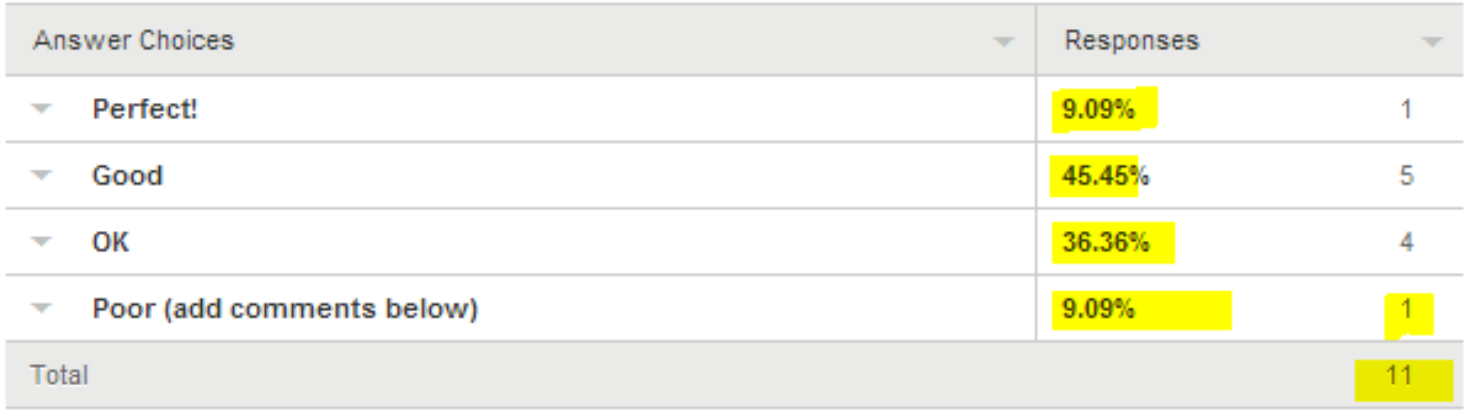

Comments (1) 
Comments (1)

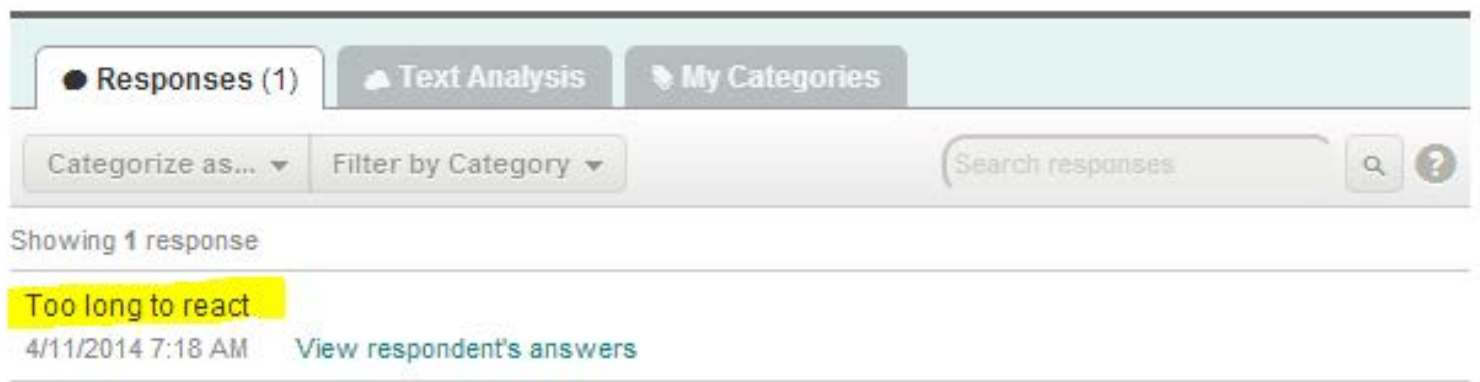

Just over half of the users have a favorable opinion about how they think ICT should be organized and perform. This is also an area that needs improvement based on the input of some users. A more direct survey will be published to get a better feel for what users really want from an "ideal" service desk operation. 


\section{How do you rate the communication and follow-up on problem resolution?}

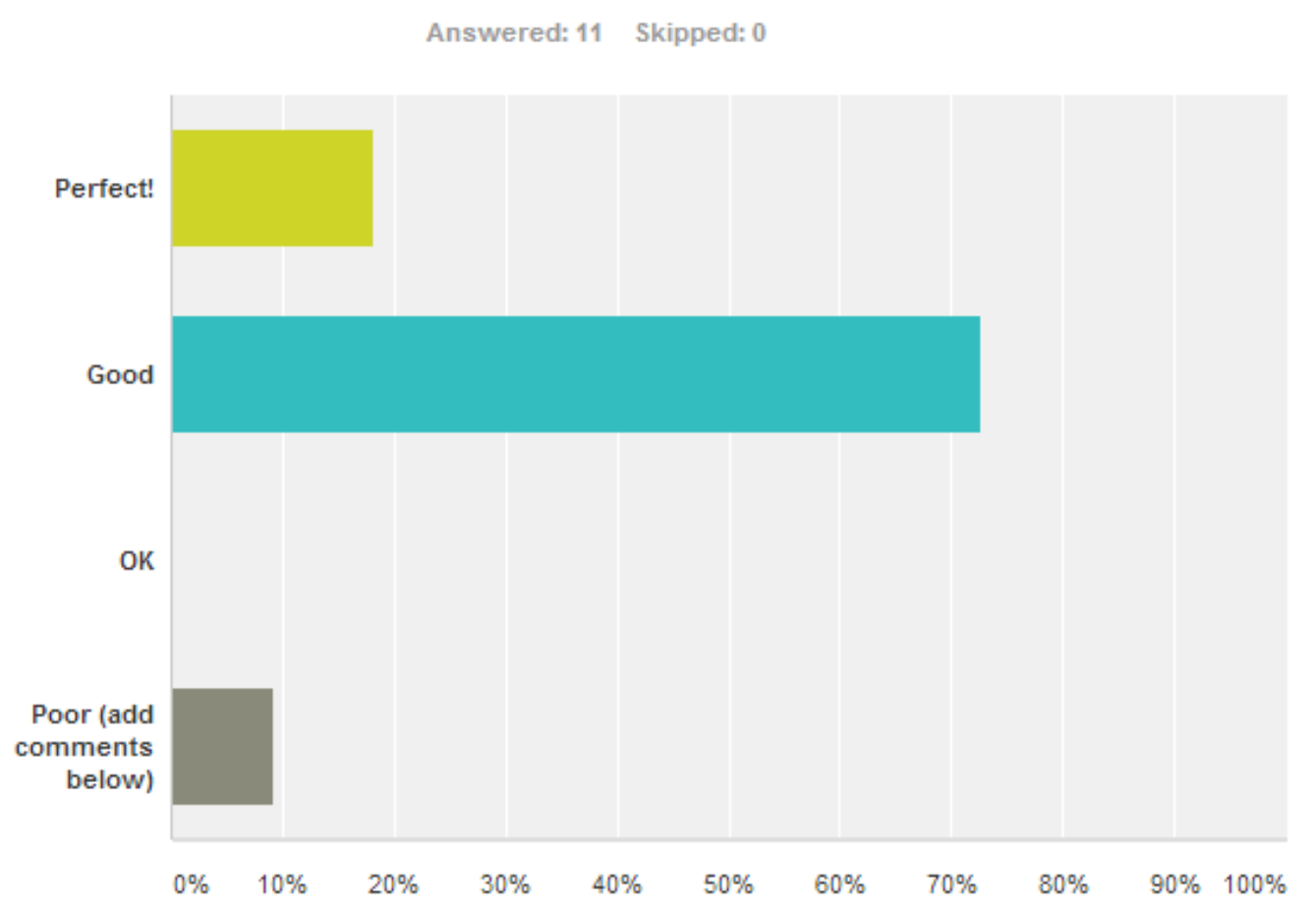

\begin{tabular}{|c|c|c|c|}
\hline \multicolumn{2}{|c|}{ Answer Choices } & \multirow{2}{*}{$\begin{array}{l}\text { Responses } \\
18.18 \%\end{array}$} & \multirow{2}{*}{2} \\
\hline$\checkmark$ & Perfect! & & \\
\hline 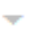 & Good & $72.73 \%$ & 8 \\
\hline$\checkmark$ & OK & $0.00 \%$ & 0 \\
\hline$\checkmark$ & Poor (add comments below) & $9.09 \%$ & 1 \\
\hline \multicolumn{2}{|c|}{ Total } & & 11 \\
\hline
\end{tabular}

Comments (0)

Over $90 \%$ of users have a favorable opinion with regards to follow-up after a solution has been applied to a problem. Good follow-up is key to ensuring problems do not linger and fall through the cracks. At least 1 user has expressed concern in this area. We will focus on all open issues to ensure proper follow-up for all issues for all users. 


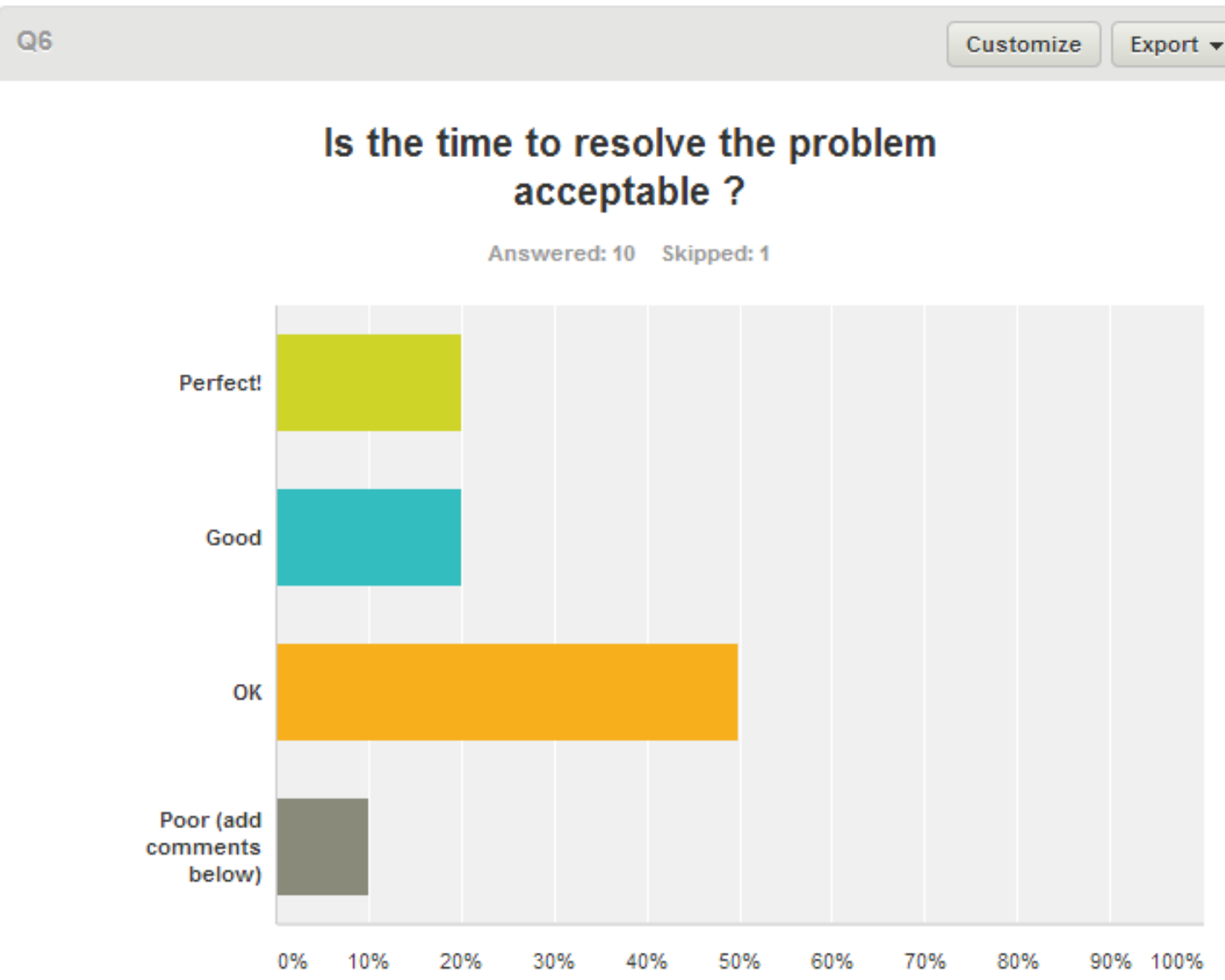

\begin{tabular}{|l|lc}
\hline Answer Choices & \multicolumn{2}{l}{ Responses } \\
\hline Perfect! & $20.00 \%$ & 2 \\
\hline$\quad$ Good & $20.00 \%$ & 2 \\
\hline$\quad$ OK & $50.00 \%$ & 5 \\
\hline$\quad$ Poor (add comments below) & $10.00 \%$ & 1 \\
\hline Total & & 10 \\
\hline
\end{tabular}

Comments (0)

Only $40 \%$ of users have a favorable opinion with regards to the time it takes to resolve a problem. Better communication during the resolution process is most likely needed. Based on effort estimates, on average it takes approximately 45 minutes of effort to resolve an issue by the service desk. We set a benchmark of 30 minutes of effort on average to resolve. In terms of closing time (the amount of time between opening and closing a ticket), there is no real data yet. Cases where there must be physical intervention (on-site activity) may be to blame for this statistic as there is little on-site presence related to infrastructure support. Some changes will need to take place to improve this situation. Better education about alternative working scenarios/equipment would also be helpful. 


\section{How do you rate the communication skills of the service desk?}

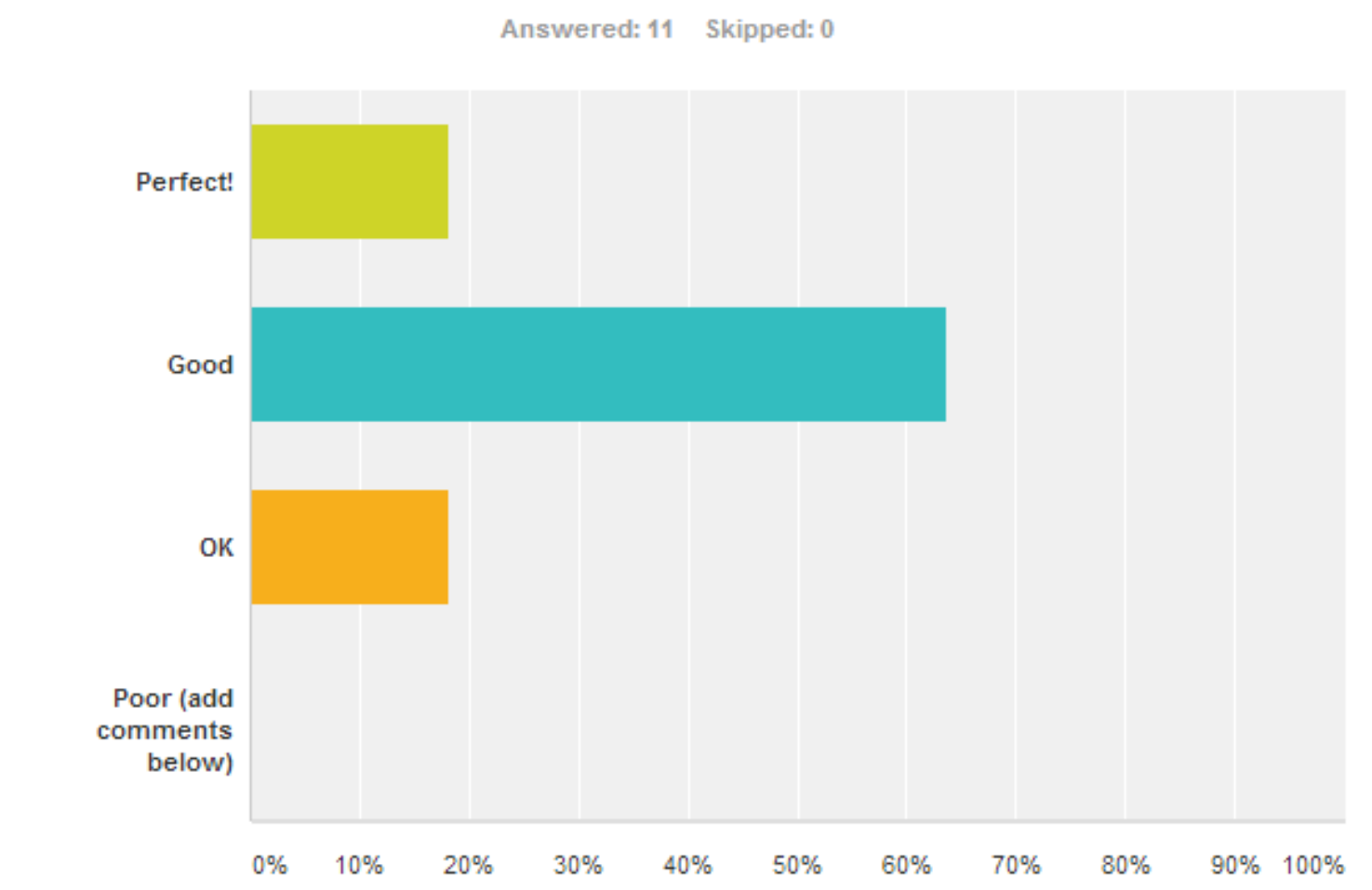

\begin{tabular}{l|lc}
\hline Answer Choices & Responses \\
\hline Perfect! & $\mathbf{1 8 . 1 8 \%}$ & 2 \\
\hline$\quad$ Good & $\mathbf{6 3 . 6 4 \%}$ & 7 \\
\hline$\quad$ OK & $\mathbf{1 8 . 1 8 \%}$ & 2 \\
\hline$\sim \quad$ Poor (add comments below) & $\mathbf{0 . 0 0 \%}$ & 0 \\
\hline Total & & 11 \\
\hline
\end{tabular}

Comments (0)

Over $80 \%$ of users have a favorable opinion of the technician"s ability to communicate technical knowledge as it relates to the problem cause or solution in a way that is understandable. 


\section{Overall Quality of the Servicedesk?}

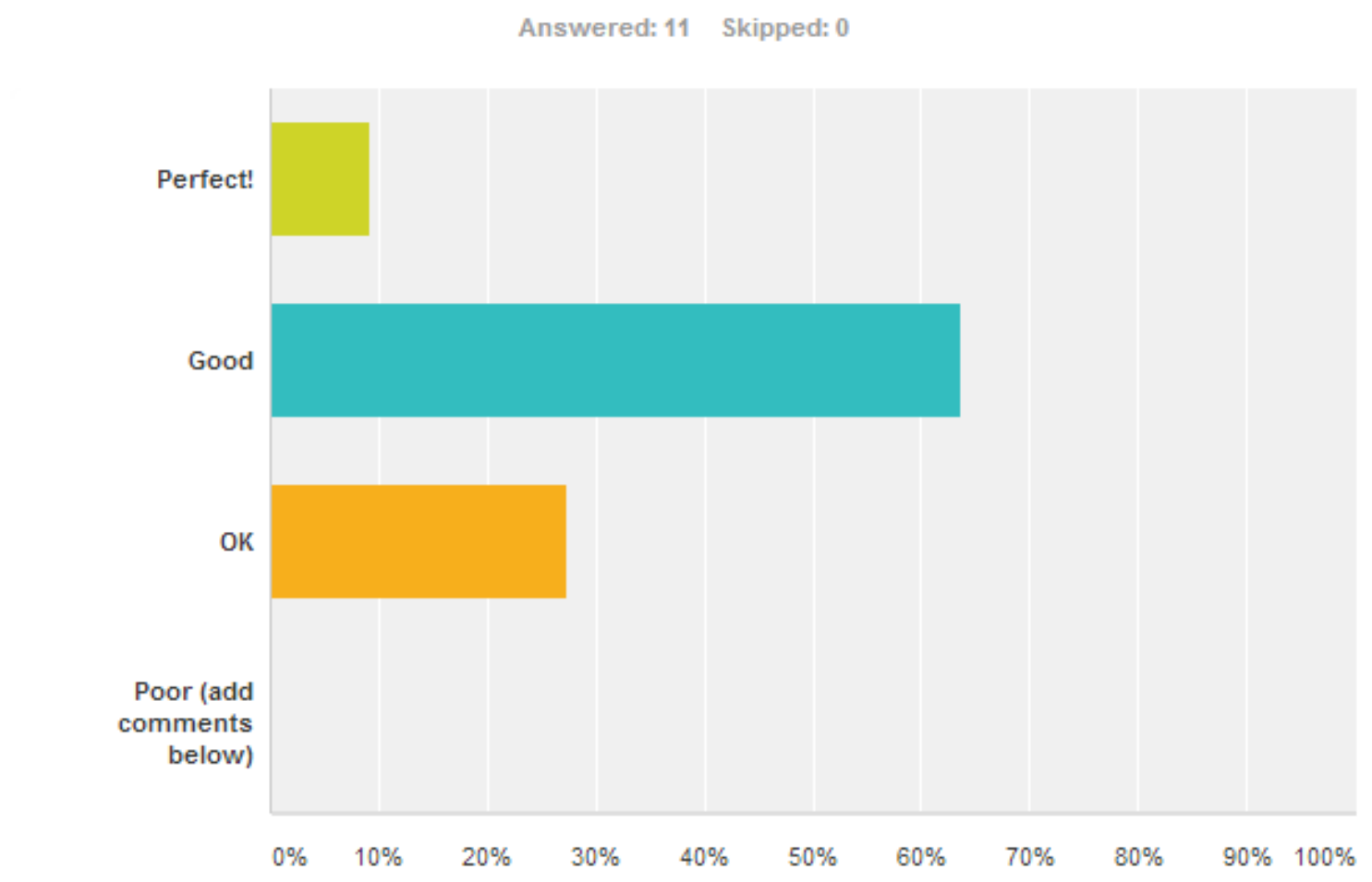

\begin{tabular}{|c|c|c|c|}
\hline \multicolumn{2}{|c|}{ Answer Choices } & \multirow{2}{*}{$\begin{array}{l}\text { Responses } \\
\mathbf{9 . 0 9 \%} \\
\end{array}$} & \multirow{2}{*}{1} \\
\hline$\checkmark$ & Perfect! & & \\
\hline$\checkmark$ & Good & $63.64 \%$ & 7 \\
\hline 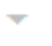 & OK & $27.27 \%$ & 3 \\
\hline$\checkmark$ & Poor (add comments below) & $0.00 \%$ & 0 \\
\hline \multicolumn{3}{|c|}{ Total } & 11 \\
\hline
\end{tabular}

Comments (2)

Over $70 \%$ of users have a favorable opinion of the service desk as a whole. The absence of negative feedback in this area means that we are moving in a positive direction. More can be done, of course to improve those numbers to $100 \%$ favorability. 


\begin{tabular}{|c|c|c|c|c|}
\hline - Responses (2) & Text Analysis & My Categories & & \\
\hline Categorize as.... & Filter by Category $\overrightarrow{ }$ & & Search responses & Q \\
\hline
\end{tabular}

Hard to judge as I have not dealt a lot with them.

4/10/2014 2:31 PM View respondent's answers

I've only called the service desk once so I don't have much experience with them. However, they handled the situation well and I didn't have any problems.

4/10/2014 10:43 AM View respondent's answers

This survey is the feedback opportunity since employing a service desk entity. I will take this information to the service desk team so we can learn more about what is making the system weaker and shore up those areas. 


\section{Exhibit 6: A Page of the OneNote File Shared with Pivotal}
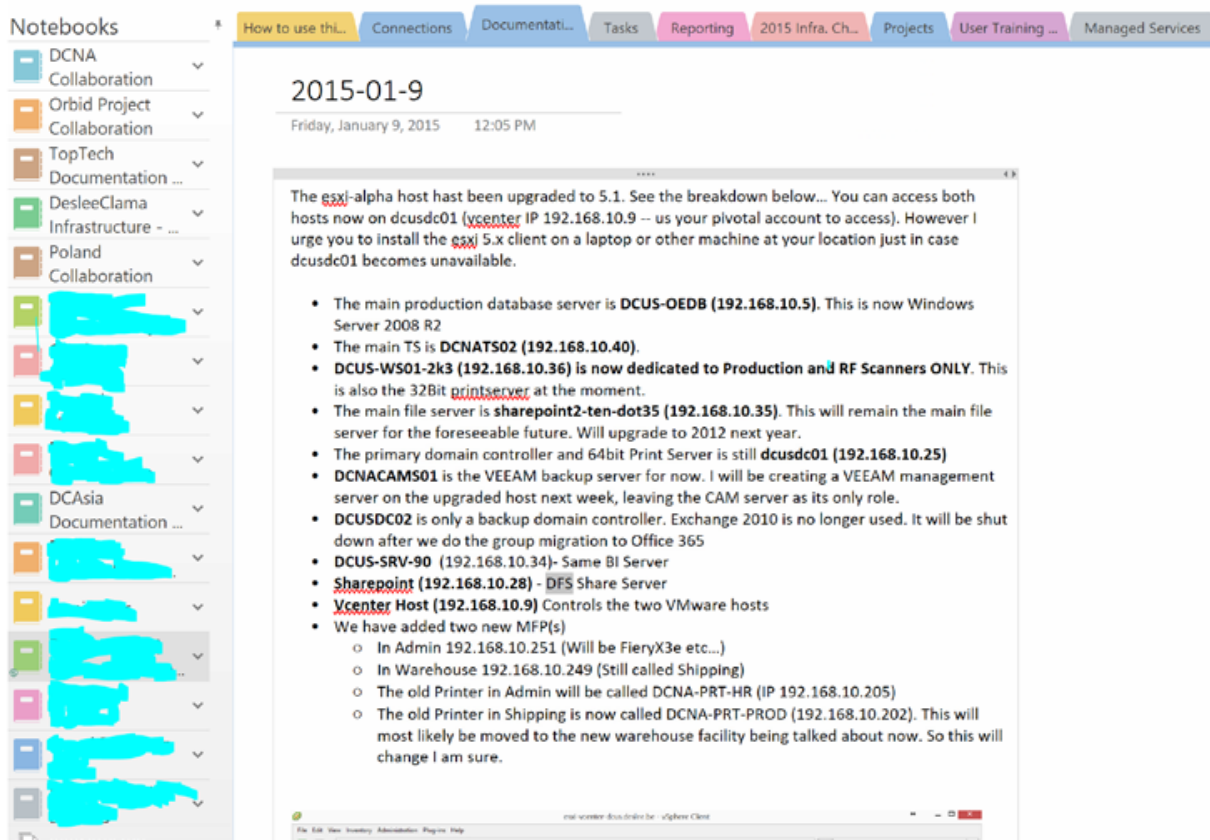

- The main production database server is DCUS-OEDB (192.168.10.5). This is now Windows Server 2008 R2

- The main TS is DCNATSO2 (192.168.10.40).

DCUS.WS01-2k3 (192.168.10.36) is now de

- is also the 32 Bit ptintservet at the moment.

The main file server is sharepoint2-ten-dot35 (192.168.10.35). Th.
server for the foreseeable future. Will upgrade to 2012 next year.

- The primary domain controller and 64bit Print Server is still dcusdc01 (192.168.10.25)

- DCNACAMS01 is the VEEAM backup server for now. I will be creating a VEEAM management

- server on the upgraded host next week, leaving the CAM server as its only role.

- Server on the upgraded host next week, leaving the CAM server as its only role.
DCuSDCO2 is only a backup domain controller. Exchange 2010 is no longer used. It will be shut

down after we do the group migration to Office 365

DCUS-SRV-90 (192.168.10.34)-Same BI Server

- Sharepoint (192.168.10.28) - DFS Share Server

Ycenter Host (192.168.10.9) Controls the two VMware hosts

We have added two new MFP(s)

o In Admin 192.168.10.251 (Will be FieryX3e etc...)

in Warehouse $192: 16810249$ (Stlll colled Shipping)

The old Printer in Admin will be called DCNA-PRT-HR (IP 192.168.10.205)

The old Printer in Shipping is now called DCNA.PRT.PROD (192.168.10.202). This will

most likely be moved to the new warehouse facility being talked about now. So this will change l am sure.

Using Mantis

Software Location

Users and Devices

- Old - Scanner Architec

Network Topology and WI

KYC-Gateway WFI AP

Mansged Switches

LAN Config

Terastation NAS ISCSI Tar

Virtual infrastructure Chan

2015-01-9

Printer Changes

Mobile Communications

HP WFI Infrastructure

HFF Finishing Schaeffer $\mathrm{W}$

Schaeffer Training Server

Adding E-mail locations t

Adding FTP locations to $t$

School Street Warehouse

Camera Access Document

Configuring the Blueiri

Board Room Conference

Makeover

Showroom Conference St

LGL - KYC 0247 Machine

LGL Imventory DCNA

LGL KYC Estonia

LGL KYCIDC 
Exhibit 7: 2014 Categorical View of Incidents and Effort Hours

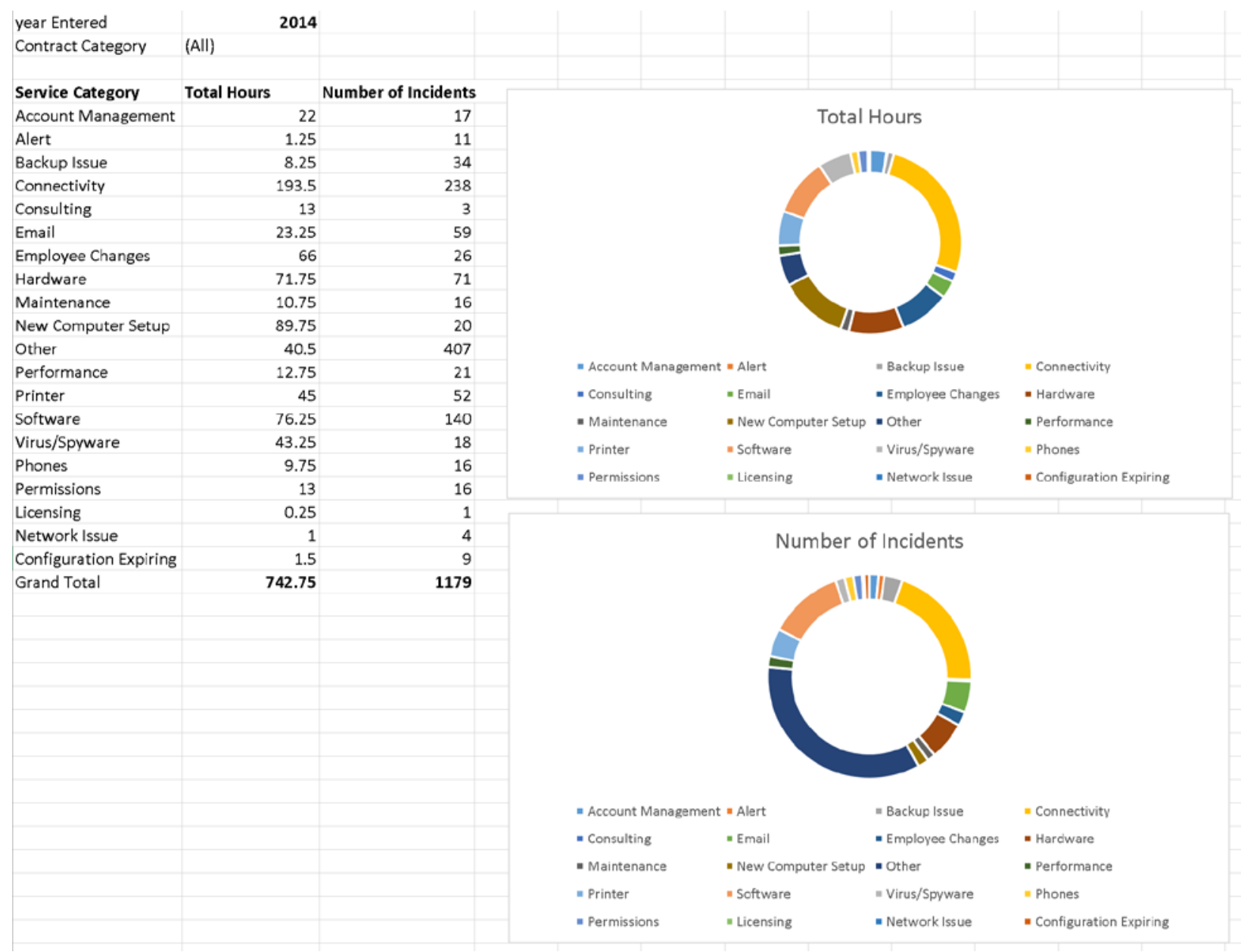

